\title{
AC 2012-3201: A DUAL UNDERGRADUATE/GRADUATE COURSE IN SPACE MISSION FAILURES
}

\section{Dr. Sanjay Jayaram, Saint Louis University}

Sanjay Jayaram is an Associate Professor in the Aerospace and Mechanical Engineering Department of Saint Louis University. He obtained his Ph.D. degree in the area of mechanical engineering from University of Central Florida in 2004. He teaches control systems/mechatronics, space systems engineering and astronautics related courses as well as engineering sciences courses. He has published several peer reviewed journal and conference papers in these areas. His research areas are space systems, robust fault tolerant control, nonlinear control, adaptive control, small spacecraft design, high performance spacecraft components, mechatronics, real-time health monitoring, and diagnostic methodology.

\section{Dr. Michael Swartwout, Saint Louis University}

Michael Swartwout is an Assistant Professor in aerospace and mechanical engineering at Parks College, Saint Louis University. He earned his Ph.D. in aeronautics and astronautics from Stanford University. As a graduate student, he led the development of the student-built satellite, Sapphire, which was launched in 2001. Starting at Washington University in St. Louis and continuing at Parks, Swartwout has been involved in four student missions on the space shuttle and numerous balloon-launched student experiments, as well as flights on NASA's Microgravity University. His student teams have been in five consecutive Air Force University Nanosat competitions, taking second place three times. Their next student satellite, COPPER, is slated to launch in June 2012 as part of NASA's ELANA-IV flight. Swartwout's research interests center on the design and operation of low-cost space systems. 


\title{
A Dual Undergraduate/Graduate Course in Space Mission Failures
}

\begin{abstract}
$\underline{\text { Abstract }}$
Teaching and learning about reasons for engineering failures offer students valuable insights and practical experience into the technical, project management, experimental, ethical, and professional issues faced by practicing engineers on a daily basis. Even though space missions and spacecraft systems are designed to operate in the presence of multiple failures, occasionally, these systems will still fail spectacularly. The reasons for failure include incorrect design decisions, operator error, manufacturing defects, and lack of proper subsystem and system level integration and test. The odds of these failures occurring can be significantly reduced through good systems engineering practice. But, in some cases, the very systems engineering practices themselves directly contribute to the failure. The lessons learned from success and failures are a powerful aid to understanding, but it is very difficult to find appropriately-scoped projects that can supplement classroom activity.
\end{abstract}

The aerospace engineering faculty has created a candidate course in the area of space mission failures for undergraduate and graduate students. This dual undergraduate and graduate course was developed to introduce the fundamentals of good systems engineering practice to space systems engineering students. In this paper, we will outline our approach for teaching space mission failures by presenting the fundamental structure of the course with course objectives and various topics covered. The paper will also present the student assessment as well as the course assessment and example case studies developed by the students.

\section{Introduction}

Teaching and learning about reasons for engineering failures offer students valuable insights and practical experience into the technical, project management, experimental, ethical, and professional issues faced by practicing engineers on a daily basis. Even though space missions and spacecraft systems are designed to operate in the presence of multiple failures, occasionally, these systems will still fail spectacularly. The reasons for failure include incorrect design decisions, operator error, manufacturing defects, and lack of proper subsystem and system level integration and test. The odds of these failures occurring can be significantly reduced through good systems engineering practice.

It is typically recognized that failure is a common occurrence and that future success is often a consequence of our reaction to failures ${ }^{1}$. Hazard analysis which relies on engineering practice and judgment to identify, classify, and manage risk has continued to have an important role in foreseeing and preventing critical system failure ${ }^{2,3}$. Failure's role in engineering; including its value in design, design revisions and failure as a source of engineering judgment has been studied $^{4,5}$. The continued failure of important complex systems has led to assess the question as to how the systems fail despite everything thought to be necessary in the way of process being done $^{6}$.

Several engineering curriculums do offer courses based on either laboratories or case studies to understand the importance of failures in design as a teaching $\operatorname{aid}^{7,8,9,10}$. The lessons learned from success and failures of space systems are a powerful aid in understanding the systems 
engineering process, but it is very difficult to find appropriately-scoped projects that can supplement classroom activity.

The aerospace engineering faculty has created a candidate course in the area of space mission failures for undergraduate and graduate students. This course introduces five heuristics of space mission failures: (1) understand the systems engineering process, (failure prevention and contribution towards failure $)^{11,12,13}$, (2) Recognize and explain the tradeoffs among budget, schedule, performance and risk, including the consequences of these trades, (3) Identify the six categories of mission failure (environment, design, assembly, parts, operation and budget), (4) Use engineering documents and failure reports to classify mission failures by cause and type, and, (5) applying these principles to university spacecraft development projects. A series of case studies in failures (rockets, spacecraft, rovers, etc.) was used to illustrate these principles and the new vulnerabilities they introduce.

\section{Course on Space Mission Failure}

The title of the new three-credit hour dual senior-level technical elective and graduate course is Space Mission Failures. This course is a seminar/lecture based format where the lecture/seminar is held twice a week for one hour and fifteen minutes each. Significant amount of lectures for the course was team taught by both Dr. Jayaram and Dr. Swartwout, while lecture on some specific topics were presented by enrolled graduate students. The pre-requisites for the course were Astrodynamics, and Space Mission Analysis and Design. From the course on Astrodynamics, students have knowledge of basic orbital mechanics and analysis, orbital and interplanetary transfers, rocket dynamics and spacecraft dynamics. From the course on Space Mission Analysis and Design, the students are exposed to topics like major subsystems of a spacecraft system. Space environment, propulsion system, power system, structural design, spacecraft dynamics and attitude control, orbit mechanics, thermal control, communications, and ground segments, command and data handling.

The grading scheme for students with undergraduate and graduate standing was slightly different. Both undergraduate and graduate students were commonly graded on homework, scheduled quizzes, group powerpoint presentation on specific topics, two group projects and group/individual case study development, and mid-term and final group project presentation. However, in addition to the assignments and activities described above, students earning graduate credit were required to prepare and present a term-paper case study on a recent mission failure not covered in class, as well as lead the class investigation/discussion by giving lecture on some selected topics as well as one of the case studies covered in class.

The main objectives of the course are:

- Understand the systems engineering process, including the motivation for having one.

- Recognize and explain the tradeoffs between budget, schedule, performance and risk, including the consequences of these trades

- Identify the six categories of mission failure (environment, design, assembly, parts, operation and budget) and the systems engineering tools developed to address each

- Use engineering documents and failure reports to classify mission failures by cause and type 
- Explain the new failure modes introduced by standard systems engineering practices, and the methods to mitigate these failure modes.

The textbook used was; Space Systems Failures, ed. by Harland and Lorenz. (strongly recommended) along with Space Mission Analysis \& Design, ed. by J. R Wertz (as reference). Along with this, several journal and conference articles along with a series of technical failure reports as published by NASA, ESA, etc. and freely available online were also used. The course was first taught during the Spring 2011 semester. The course was again scheduled to be taught in Spring 2012 semester, but scheduling conflicts prevented this. The course will again be taught during the Fall 2012 semester. It is intended that improvements and revisions to the course learning materials will be made during Fall 2012 course offering.

\section{$\underline{\text { Lecture Content }}$}

A list of topics covered in the course and their intended sequence of presentation is shown below. Each topic was for duration of one to two weeks.

1. Introduction - A brief introduction to various space mission failures based on both technical and management reasons

2. Fundamentals of the Systems Engineering Process - Review of the systems engineering process from customer needs to system requirements; benefits of a disciplined systems engineering process; importance of developing sound mission statement, systems requirement document; importance of trade-off studies and the design process documentation; management issues; systems integration and testing - its importance, while highlighting the fact that most of the space missions fail technically due to lack of better system integration and testing practices. Discuss historical examples and case studies.

3. The Relation between Risk and Failure - Fundamental definitions of Risk and Failure and their importance in successful space mission design. Concepts on how risk is associated with design issues are highlighted. The students are provided a better understanding how risk influences the decisions on technical issues as well as management issues (such as project cost and schedule). Students are allowed to discuss and comprehend several questions, like,

a. How much risk is acceptable before failure occurs?

b. What is the influence of risk on cost and schedule?

c. How to identify and mitigate risks?

4. Environmental Contributions to Mission Failure - An in-depth look at various environmental factors that contribute to the failure of a space mission is analyzed. Specifically, environmental factors influencing the success of a space mission during pre-launch (i.e. integration and test with the launch vehicle), actual launch of the rocket and on-orbit environmental conditions (like radiation, atmospheric conditions, plasma and neutral environment, etc.).

5. Failures in Design - Though the system engineering process requires design analysis, testing and verification process, design failures remain a major source of failure of spacecraft components and subsystem. Detailed analysis of spacecraft component design and analysis based on the space environment that the spacecraft will be 
operational are explored. A design failure occurs when the strength of parts or components, purchased or manufactured, proves insufficient to withstand the loads experienced during the mission. If the load experienced was associated with a phenomenon not yet understood, or of a magnitude not yet recorded, the failure is usually assigned to environmental causes. Design failures are, therefore, associated with oversight or error.

6. Human Errors - Factors due to human errors affecting and influencing the success or failure of a space mission are explored. Specifically, three important concepts, (i) Assembly Errors, (ii) Parts Manufacturing Errors, and (iii) Operator Errors are investigated and their effect on space missions' success. Importance of proper documenting of design procedures, assembly and operational procedures are stressed. Critical issues with documentation of parts as well as testing and manufacturing data for various components are discussed. Consequences of such errors to space mission budget, schedule and mission timeline are also discussed.

7. Budgetary Failures - Major factors influencing and affecting cost over-runs of space missions are discussed here. Traditional tendency of budgeting majority of the cost on design, and analysis phase of the spacecraft rather than on spacecraft integration and testing is explored. Historic examples are provided and discussed.

8. Statistics for failure - The use of statistical distributions to model failure data and an introduction to elementary reliability theory

9. Success Stories in Systems Engineering - Example case studies of successful space missions that implemented proper systems engineering process are presented.

\section{Course Group Projects}

Since there were two group projects in the course, the students were grouped into two teams, where both undergraduate and graduate students were mixed and evenly distributed across the teams.

\section{Project 1: Systems Engineering Process for a Student-Built Spacecraft Design}

This project required the students to explore the traditional systems engineering process that is followed by NASA or DoD and to analyze how that process can be implemented in a university setting for student-built spacecraft designs. The groups were required to identify four major parameters that affected student-built spacecraft design activity, namely, Cost, Schedule, Risk, and Performance.

Both student groups had similar final conclusions from their analysis and findings, which is summarized below:

"NASA uses the "top-down" mission design as compared to the "bottoms-up" method used by universities. NASA is driven by performance and schedules due to its substantial resources provided by taxpayers. University missions are driven by cost and performance since schedules are very flexible due to the fluctuation of resources and staffing as students come and go on a project. Universities have extremely limited resources and choose their payload/missions to fit 
said constraints”.

Figure 1 shows the comparison between NASA and University Spacecraft Design Systems Engineering Process for the four parameters chosen

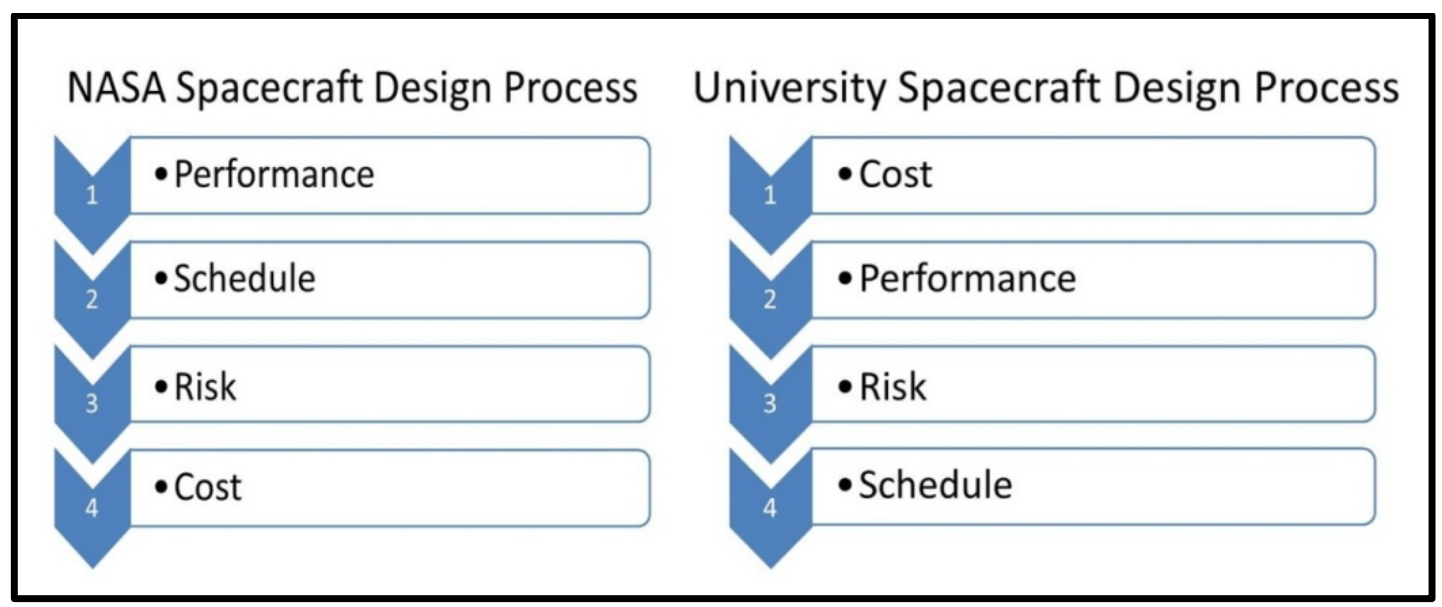

Figure 1: NASA versus University Systems Design Process

Project 2: Small Satellite Reliability: Statistical Analysis with an Emphasis on University Spacecraft

In this project, the groups were required to perform extensive literature search on various spacecraft subsystem failures, which falls under the class of 1-100 kilogram spacecraft that were launched over the last thiry years. The specific tasks in the project were as follows:

$>$ Develop spacecraft failure database - collection of on-orbit failure data and the development of a database for all satellites under $100 \mathrm{~kg}$.

$>$ Data censoring and sorting - representing the data into a useful form for analysis.

$>$ Parametric and Non-parametric Reliability Analysis - Non-parametric reliability of collective on-orbit failure using a Kaplan-Meier Estimator (KME) was studied and a Weibull distribution was calculated to fit the data.

A group report discussing the results and conclusion

Some representative results from the project reports are shown below. Figure 2 shows Kaplan Meyer Estimator analysis for the university spacecraft on-orbit reliability, whereas Figure 3 shows the Weibull distribution for university-class spacecraft failure analysis. 


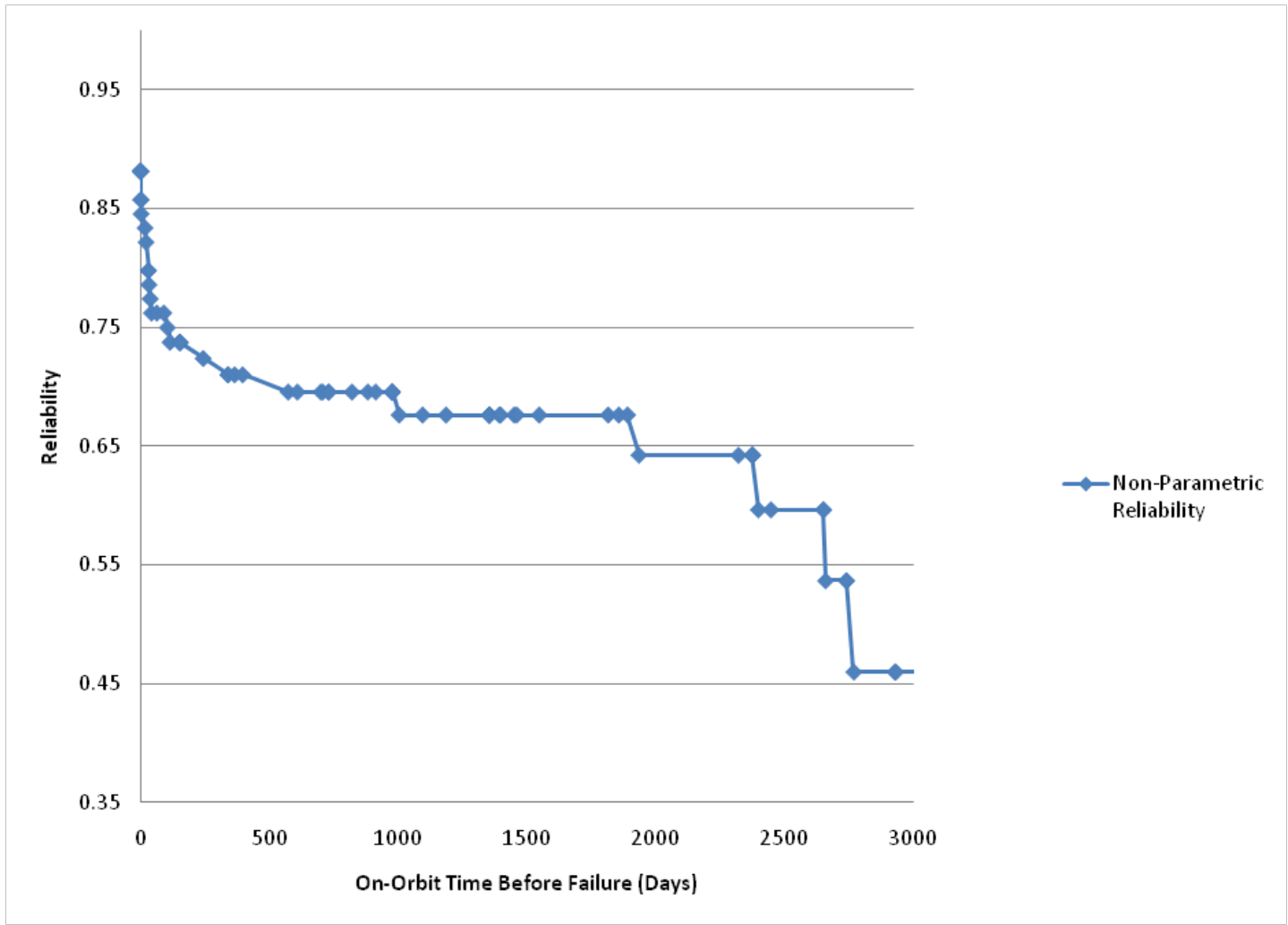

Figure 2: Kaplan Meyer Estimator analysis for the university spacecraft on-orbit reliability

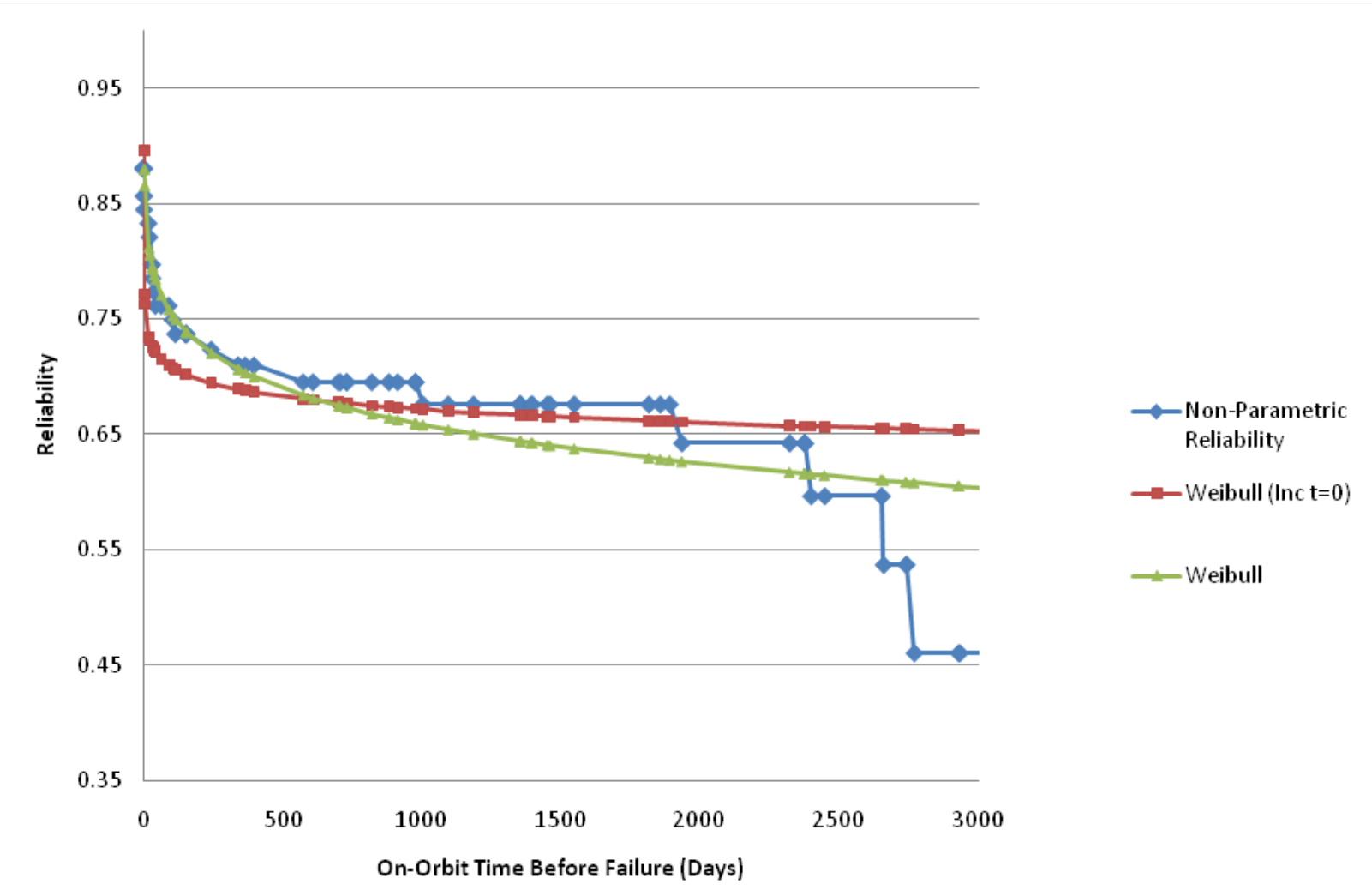

Figure 3: Weibull distribution for university-class spacecraft failure analysis. 


\section{Course Case Studies}

This was an assignment to develop engineering case studies based on technical failure reports as published by NASA, ESA, etc., that are freely available. The undergraduate students were required to develop a group case study, whereas, the graduate students where each required to develop an independent case study. The following fundamental issues were required to be addressed:

$>$ Why the mission failed?

$>$ What were the reasons for failure? Taking a deeper look into why this mission failed. You can look at this from both technical perspective (looking at six attributes environment, design, assembly, parts, operation and budget) and nontechnical perspective (project management, team work, communications etc.)

$>$ What was the outcome of the failure reports? This includes solutions and recommendations proposed.

$>$ What is your observation? What alternative solution would you have proposed? Could this mission be done better? If so, how?

Some example case studies from graduate students are provided below (only executive summaries):

\section{Case Study 1: NASA DART Mission}

"The Demonstration of Autonomous Rendezvous Technology (DART) program began in May 2001 as a part of a NASA Research Announcement (NRA) from the 2nd Generation Reusable Launch Vehicle Program (2GRLV). The DART program was developed to demonstrate that a spacecraft could rendezvous and perform proximity operations with an orbiting satellite, completely autonomously. On April 15, 2005, DART was successfully launched from Vandenberg AFB, California, to begin its four (4) phase, 24-hour mission. After a successful rendezvous with the orbiting satellite, ground operators noticed anomalies regarding excess fuel burn from DART's propulsion system. During the proximity operations phase of the mission, $D A R T$ crashed into the target spacecraft and transitioned into its departure and retirement phase before completing key mission objectives. Eleven (11) hours into the mission, DART entered the final, retirement orbit after completing only 11 of the 27 requirements set forth for a successful mission. Post-mission analyses of telemetry data uncovered multiple errors in design, testing, and planning which contributed to a "Type A" mishap which called for a Mishap Investigation Board (MIB) review. Alternative solutions and recommendations for future mission improvements have also been considered".

\section{Case Study 2: Apollo 13 Mission}

This case study summarizes and analyzes the infamous Apollo 13 mission failure and safe return of the flight crew consisting of NASA astronauts James A. Lovell, Command Module pilot Jack L. Swigert, and Lunar Module pilot Fred W. Haise. The failure is analyzed from take-off to reentry and all that happened in between. The study also includes the findings from the Apollo 13 Review Board chartered by NASA to find the ultimate reason for the mission's failure. As the case study explains, Apollo 13 suffered from a series of unfortunate minor failures that escalated 
into major complications and resulted in the spacecraft becoming unfit for moon landing, requiring immediate return to Earth.

To individually assess undergraduate student performance in the course, an individual assignment on developing two-page executive summary on a successful space mission was assigned. The executive summary was required to address the following components:

$>$ Choose a program from NASA, DoD or ESA which was a successful mission.

$>$ Develop an Executive Summary (not more than 2 pages) addressing the following questions

o What was the objective of the mission

o Investigate the reasons why the mission was successful.

o You should observe the "success" from systems engineering point of view, which will include technical design, schedule, cost, risk management, project management etc.

$>$ Give your own assessment of the results that you find.

$>$ Briefly discuss (in 3-4 lines) what you have learnt from this exercise

An example executive summary is shown below:

\section{Successful Systems Engineering - Voyager 2}

At the end of the 1960s, in conjunction with the gigantic strides in space exploration already taking place at NASA, a set of unmanned missions was conceived to explore the depths of Earth's neighborhood, the Solar System. Development of this mission began and continued into the following decade, ultimately leading to the launch of a pair of spacecraft, Voyager 1 and Voyager 2, in 1977. The timing of these missions coincided with an advantageous alignment of the outer gas giant planets in order to facilitate a new propulsion technique for interplanetary missions. Increased knowledge of "gravity assist" flybys laid the framework for mission that could explore further than ever before, and the Voyager missions were designed from the beginning to do just that. By launching during a certain window of time, the spacecraft would visit all four gas giants and utilize the velocity change caused by a flyby of each in order to increase velocity required to continue to the next destination. Ultimately, Voyager 2 did visit all four of the gas giants, and as it remains today, is the only spacecraft to have visited both Neptune and Uranus.

\section{Student Assessment and Course Feedback}

The assessment methods for the course consist of assignments, exams, and group projects. The student work was broken into the following categories, with the weighting on their grade shown (Table 1): 
Table 1: Grading Scheme

\begin{tabular}{|c|c|c|}
\hline Assessment Method & Undergraduates & Graduates \\
\hline Homework & $5 \%$ & $5 \%$ \\
\hline Two Group Projects & $25 \%$ & $25 \%$ \\
\hline Classroom Discussions & $40 \%$ & $40 \%$ \\
\hline $\begin{array}{c}\text { Classroom Discussions + } \\
\text { Lecture Presentation }\end{array}$ & & \\
\hline Group Case Study & $15 \%$ & $30 \%$ \\
\hline Individual Case Study & $15 \%$ & \\
\hline $\begin{array}{c}\text { Successful Systems } \\
\text { Engineering Assignment }\end{array}$ & & \\
\hline
\end{tabular}

The classroom discussions (for undergraduates) were based on the powerpoint presentation on a particular subject matter. During and at the end of the presentation, students from other groups as well as graduate students had informal discussions. Students were assessed based on their responses to questions and how they would approach in explaining their viewpoints. At the end of the course, a student survey was conducted in order to assess whether the students have achieved the expected outcomes. Eleven students took the class in Spring 2011 and only eight students completed the survey. In the survey, students were asked to respond to statements by providing a score from one to five indicating how effective the course experience was at meeting a specific objective or to what degree they agreed with the statement. A score of five indicated that the course did an excellent job at meeting the specified goal or they strongly agreed with the statement, whereas a score of one indicated that the course did not meet the specified goal or they strongly disagreed with the statement. Students were also asked to provide detailed responses to various questions on each survey. A summary of the results generated for the survey given to the students to assess the effectiveness of the course is provided in Table 2.

Table 2: Course Outcome Survey

\begin{tabular}{|l|c|}
\hline & Average \\
\hline $\begin{array}{l}\text { The course helped me understand the importance of failure and failure analysis of } \\
\text { engineering systems }\end{array}$ & 4.375 \\
\hline $\begin{array}{l}\text { The course helped me to understand the reasoning behind failure analysis, } \\
\text { particularly for space systems }\end{array}$ & 4.5 \\
\hline $\begin{array}{l}\text { This course was helpful in developing new skills. I gained an excellent } \\
\text { understanding of concepts in this field and the course helped me to become a } \\
\text { more critical thinker. }\end{array}$ & 4.25 \\
\hline $\begin{array}{l}\text { Literature Research Paper presentations and Case Study developments helped } \\
\text { understand the overall perspective of Space Mission Failures }\end{array}$ & $\mathbf{4 . 6 2 5}$ \\
\hline $\begin{array}{l}\text { The course content was relevant and it helped in understanding the failure } \\
\text { analysis }\end{array}$ & 4.5 \\
\hline
\end{tabular}

Some selected student comments on overall experience with the course:

$>$ I enjoyed the course and would recommend it to others

$>$ Definitely a helpful course. Easy to understand 
Very educational and useful

$>$ Good to have guest speakers. Overall, good experience. Presentations helped cover the material well

$>$ I really enjoyed the course

\section{Planned Modifications for Next Offering}

The challenges associated with this new course are much the same as the challenges of any new course, although the focus of seminar-based course material delivery leads to an increased workload in preparation for the course material. Based on the feedback from students, some modifications and improvements will be implemented when the course is next offered in Fall 2012. The improvements will be concentrated on course content, and more diversified resources. It is also planned to invite guest speakers to provide an industry and/or research perspective on various topics. It was noticed, probably due to maturity and better understanding of the importance of spacecraft design related issues in their future career, that graduate students valued the seminars and put more effort on its preparation than most of the undergraduate students.

\section{Summary and Conclusions}

This new seminar-based course was implemented as a dual senior undergraduate and graduate course in the Aerospace Engineering Curriculum. The course covered a broad range of topics dealing with space mission failure issues stemming from systems engineering perspective to six categories that are directly or indirectly related to space mission failures. Based on the student feedback, there is enough evidence that the goals for student learning were achieved, for the most part. This assessment is based on overall good student performance in class assignments, and the fact that student feedback on course evaluations was overall positive.

\section{References}

[1] M. R. Louthan, "Overcoming failure”, Journal of Failure Analysis and Prevention, Volume 10, No. 4, pp. 249-250, 2010.

[2] A. J. McEvily, "Failure in Inspection Procedures: Case Studies", Engineering Failure Analysis, Volume 11, No. 2, pp. 167-176, 2004.

[3] R. L. Collins, "Process Hazard Analysis Quality”, Process Safety Progress, Volume 29, No. 2, pp. 113-117, 2010.

[4] H. Petroski, “To Engineer is Human: The Role of Failure in Successful Design”, St. martin’s Press, New York, 1985.

[5] H. Petroski, "Design Paradigms: Case Histories of Error Judgment in Engineering", Cambridge University Press, Cambridge, 1994.

[6] M.D. Griffin, "How Do We Fix Systems Engineering", 61 ${ }^{\text {st }}$ International Astronaut Congress, Prague, Czech Republic, 2010.

[7] D. Lanning, W. Lestari, S. Waterhouse, "A Laboratory-Based Course in Aerospace Engineering Failure", Proceedings of the 2010 American Society for Engineering Education Zone IV Conference.

[8] P. H. Oosthuizen, "Use of Aircraft Crash Cases in Teaching Engineering”, American Society for Engineering Education, Engineering Teaching and Learning Practices (ETLP), 2007. 
[9] N. J. Slegers, R. T. Kadish, G. E. Payton, J. Thomas, M.D. Griffin, D. Dumbacher, "Learning from failure in Systems Engineering: A Panel Discussion”, Systems Engineering, Volume 15, Issue 1, pp. 74-82, 2011.

[10] G.P. Halada, “Teaching by Disaster: The Ethical, Legal and Societal Implications of Engineering Disaster”, American Society for Engineering Education, Middle Atlantic Section Conference, 2010.

[11] J. S. Newman, "Failure Space: A Systems Engineering Look ar 50 Space System Failures”, Acta Astronautics, Volume 48, Issues 5-12, pp. 517-527, 2001.

[12] S. B. Johnson, "Success, Failure, and NASA Culture”, NASA ASK Magazine, Issue 32, 2008.

[13] L. D. Thomas, "Selected systems engineering process deficiencies and their consequences", Volume 61, Issues 1-6, pp. 406 - 415, 2007. 